\title{
SEASONAL CHANGES OF CONTAMINATION REMOVAL IN CONSTRUCTED WETLANDS SYSTEMS
}

\author{
Magdalena Gajewska \\ Piotr Kowalik \\ Hanna Obarska-Pempkowiak \\ Gdańsk University of Technology, Poland
}

\begin{abstract}
The investigation was carried out at two different hybrid constructed wetlands, which treated municipal sewage after mechanical treatment from small villages in Pomeranian Region. In all facilities first step of biological treatment were horizontal flow beds. The main difference concems configuration of the facilities and sewage distributions systems into vertical flow beds. The measurement period was divided into vegetation (from April to October) and outside vegetation seasons (from November to March) for all analysed facilities.

The results allowed for estimation of efficiency removal of different contaminations in both measurements seasons. Comparison of the amount of sewage and loads of contamination inflowing and outflowing from the facilities are presented. Achieved results make it possible to estimate the rate of organic matter decomposition and nitrogen removal in vegetation and outside vegetation seasons.
\end{abstract}

\section{KEYWORDS}

municipal sewage, constructed wetlands, contaminations removal, vegetation season

\section{INTRODUCTION}

At present in Poland increases awareness for solving the problems connected with wastewater treatment in rural areas. There is a huge gap between water supply and wastewater treatment in the countryside. In 2001 about $9.0 \%$ of sewage generated in rural areas was collected and only $3.1 \%$ was treated before discharging to the recipient. Recently an idea of treating wastewater in the constructed wetland systems has emerged. In Poland these systems have been in operation for about 20 years. Nowadays more than 100 constructed wetlands are in operation in Poland. 
KALMAR ECO-TECH'03

Bioremediation and Leachate Treatment

KALMAR, SWEDEN, November 25-27, 2003

New polish standards implemented in 2002 create better condition for emerged of constructed wetland methods. Since $1^{\text {th }}$ of December discharged sewage from less than $2000 \mathrm{PE}$ and above $50 \mathrm{PE}$ (majority of constructed wetland in Poland) has to fulfil following standards: $\mathrm{BOD}_{5} \leq 40 \mathrm{mg} \mathrm{O} / 1, \mathrm{COD} \mathrm{Cr}_{5} \leq 150 \mathrm{mg} \mathrm{O} / 1$, SS $\leq 50 \mathrm{mg} / \mathrm{dm}^{3}$ and if the outflow is discharged to the lake: $N_{\text {Tot }} \leq 30 \mathrm{mg} \mathrm{N} / 1, \mathrm{P} \leq 5 \mathrm{mg} \mathrm{P} / \mathrm{l}$. The alleviate requirements seems to be more realistic and constructed wetland ensure efficient removal of suspended solids and organic matter. Also effective nitrogen removal is possible in systems with at least two beds with horizontal and vertical flow placed as second and third biological step, these systems are so called hybrid systems. But there is still a question how low temperature in winter time influence on different contamination removal. Is the effectives high enough?

\section{METHODS}

The studies were carried out at two hybrid constructed wetlands in Wiklino near Słupsk and Darżlubie near Puck (Pomeranian Region) supplied with municipal wastewater. Both facilities were build and planted with Phragmites australis in 1994. The sewage after mechanical treatment were pumped into biological treatment which consists of beds with HF-CW and VF-CW in different configurations. The schemes of Wiklino and Darżlubie facilities is given on Fig. 1 a i b. The Wiklino consists of three beds horizontal (HF-CW I), two vertical beds which work parallel and again horizontal bed (HF-CW II). The additional bed HF-CW II was to ensure denitrification process of nitrate created in vertical beds. The Darżlubie facilities consist of five beds with mixed flow of sewage. After HF-CW I a cascade filter is located than HF-CW II bed and next are two VF-CW which work parallel and alternatively and at the end again HF-CW III is located. The cascade filter is composed of five consecutive small beds with alternatively vertical and horizontal flow. It consists of three beds with vertical and two beds with horizontal flow of sewage. After treatment in HF-CW II $50 \%$ of sewage is drained into VF-CW beds and the rest goes directly to HF-CW III. Such mixing of sewage is carried out in order to secure organic matter for intensive denitrification expected in last bed. The characteristic of analysed facilities is given in table 1 . 
KALMAR ECO-TECH'03

Bioremediation and Leachate Treatment

KALMAR, SWEDEN, November 25-27, 2003

Table 1.The characteristic of analysed constructed wetlands

\begin{tabular}{|c|c|c|c|c|c|}
\hline WWTP & $\begin{array}{l}\text { Flow, } \\
{\left[\mathrm{m}^{3} \mathrm{~d}^{-1}\right]}\end{array}$ & $\begin{array}{l}\text { Configurati } \\
\text { on }\end{array}$ & $\begin{array}{l}\text { Area, } \\
{\left[\mathrm{m}^{2}\right]}\end{array}$ & $\begin{array}{l}\text { Depth, } \\
{[\mathrm{m}]}\end{array}$ & $\begin{array}{l}\text { Unit area, } \\
{\left[\mathrm{m}^{2} \mathrm{PE}^{-1}\right]}\end{array}$ \\
\hline Wiklino & 18.7 & $\begin{array}{l}\mathrm{HF} \\
\mathrm{VF} \\
\mathrm{HF}\end{array}$ & 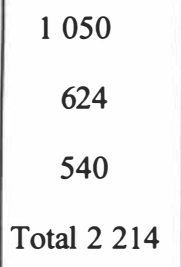 & $\begin{array}{l}0.6 \\
0.4 \\
0.6\end{array}$ & $\begin{array}{l}\begin{array}{l}7.0 \\
4.0 \\
3.4\end{array} \\
\text { Total } 14.4\end{array}$ \\
\hline Darżlubie & 56.7 & $\begin{array}{l}\text { HF-CWd } \\
\text { Cascade } \\
\text { filter } \\
\text { HF-CW II } \\
\text { VF-CW } \\
\text { HF-CW III }\end{array}$ & $\begin{array}{c}1200 \\
400 \\
500 \\
250 \\
1000 \\
\text { Total } 3350\end{array}$ & $\begin{array}{l}0.6 \\
1.0 \\
0.6\end{array}$ & $\begin{array}{c}0.5 \\
0.7 \\
1.3 \\
\text { Total } 4.1\end{array}$ \\
\hline
\end{tabular}

The averages samples of sewage were collected twice a month in the period from 1994 to 1998 in Darżlubie and from 1998 to 2000 and in 2003 for facilities in Wiklino. The samples were collected after subsequent stage of treatment in Wiklino (sampling points $1 \mathrm{~W}-4 \mathrm{~W}$ ) and in five sampling points along the Darżlubie facility (1D-5D) (Fig.1).

The measurement period was divided into vegetation (from April to October) and outside vegetation seasons (from November to March) for all analysed facilities. Length of vegetation season was estimated on the basis of vegetation time of common reed and air temperature. It was assumed that sewage temperature is not important criterion since temperature of sewage outflowing from septic tank in winter is elevated.

Measurements of physical and chemical parameters included: temperature of sewage and air, total suspended solids, $\mathrm{BOD}_{5}, \mathrm{COD}_{\mathrm{Cr}}$, ammonium nitrogen $\left(\mathrm{N}^{-\mathrm{NH}_{4}}{ }^{+}\right)$, nitrate, nitrite and organic nitrogen, total phosphorous, phosphates and alkalinity. All analyses were performed at Gdańsk University of Technology, according to the Polish Standard Methods. Removal efficiency was calculated as a quotient of contaminants concentration difference in influent $\left(\mathrm{C}_{\mathrm{o}}\right)$ and effluent $(\mathrm{C})$ after subsequent stages of constructed wetland and concentration in influent $\left(\mathrm{C}_{\mathrm{o}}\right), \eta=\left(\mathrm{C}_{\mathrm{o}}-\mathrm{C}\right) / \mathrm{C}_{\mathrm{o}}$ 
KALMAR ECO-TECH'03

Bioremediation and Leachate Treatment

KALMAR, SWEDEN, November 25-27, 2003

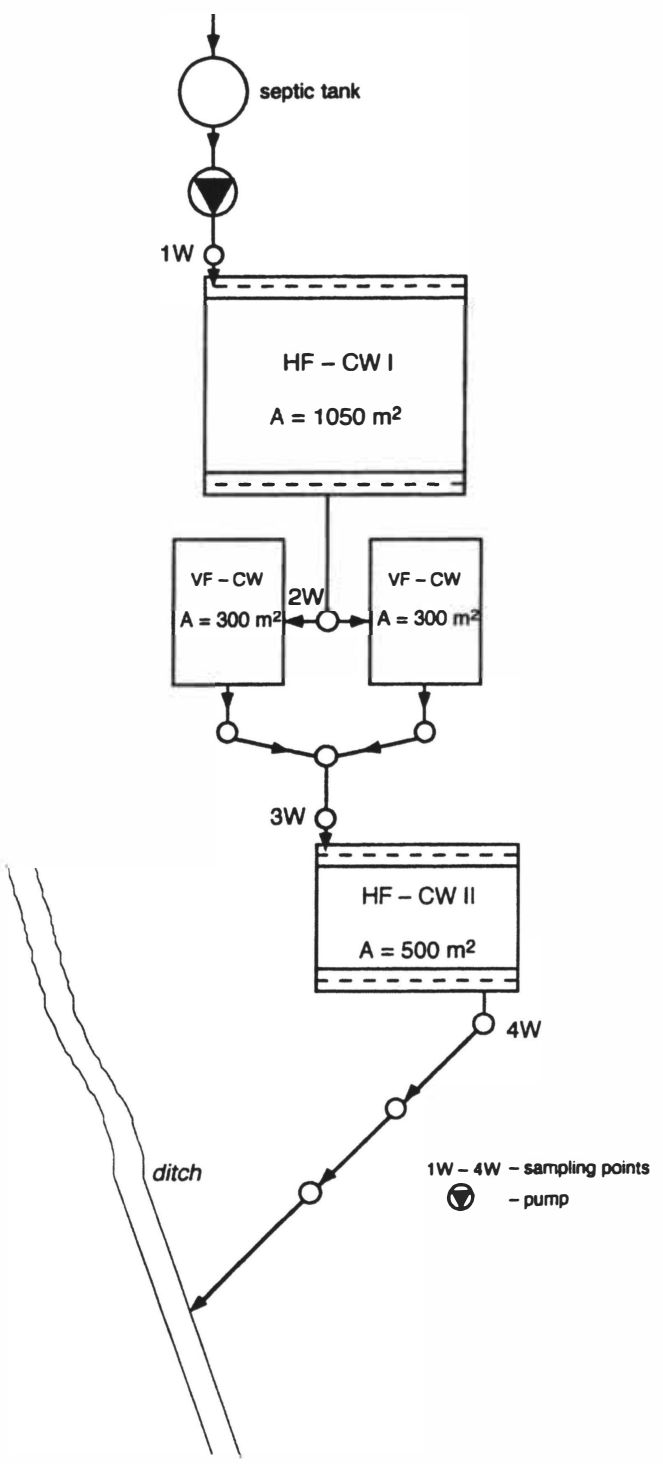

a) 
KALMAR ECO-TECH'03

Bioremediation and Leachate Treatment

KALMAR, SWEDEN, November 25-27, 2003

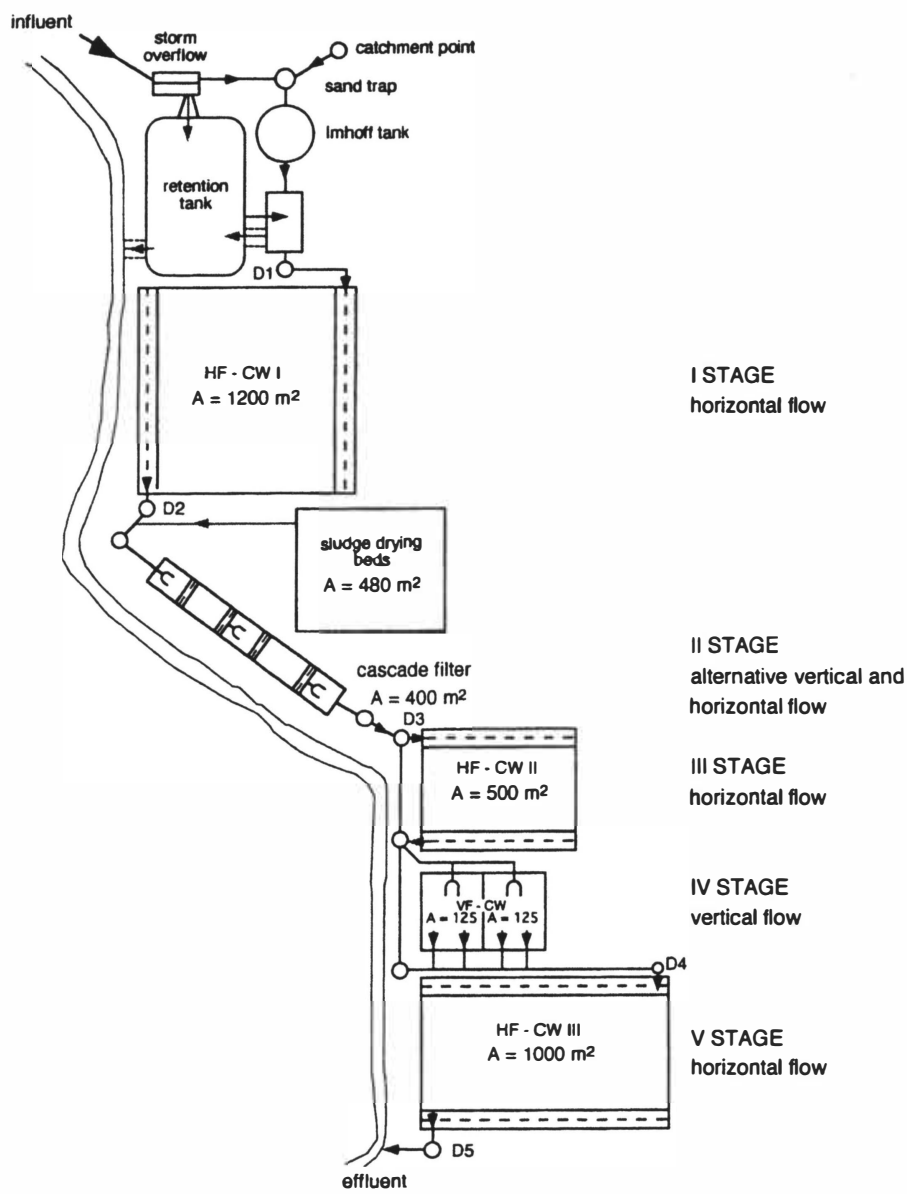

b)

Fig. 1 The scheme of constructed wetland with sampling points in Wiklino (a) and Darżlubie (b)

\section{RESULT AND DISCUSSION}

\subsection{Wiklino constructed wetlands}

During vegetation season the average amount of discharged sewage in Wiklino facilities was $19.0 \mathrm{med}^{-1}$ and was slightly higher than the average amount discharged in outside vegetation 
KALMAR ECO-TECH'03

Bioremediation and Leachate Treatment

KALMAR, SWEDEN, November 25-27, 2003

season $\left(18.4 \mathrm{~m} \mathrm{~m}^{3} \mathrm{~d}^{-1}\right)$.The average amounts of sewage outflowing from the facility were equal to $12.9 \mathrm{~m}^{3} \mathrm{~d}^{-1}$ in vegetation season and $13.9 \mathrm{~m}^{3} \mathrm{~d}^{-1}$ in outside vegetation one (Fig. 2).

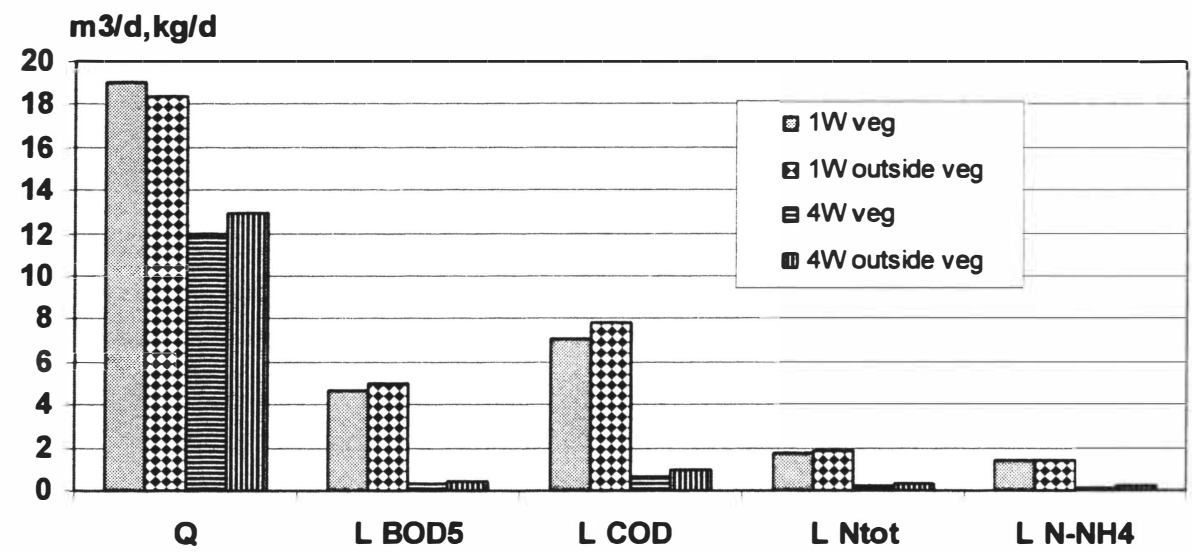

Fig. 2 The average flow of sewage and load of contaminations in sewage inflowing (1W) and outflowing $(4 W)$ from Wiklino facilities in both seasons

The average concentration of organic matter (expressed by $\mathrm{BOD}_{5}, \mathrm{COD}_{\mathrm{Cr}}$ and suspended solids) discharged to the facilities in Wiklino was higher in outside vegetation season than in vegetation one (Fig 3a). The average concentration of nitrogen compounds in sewage inflowing to the facilities during vegetation were lower than in outside vegetation season (Fig. 3b). Also in discharged sewage from the facilities the concentration of all contamination were slightly higher but still below permissible value.

a)

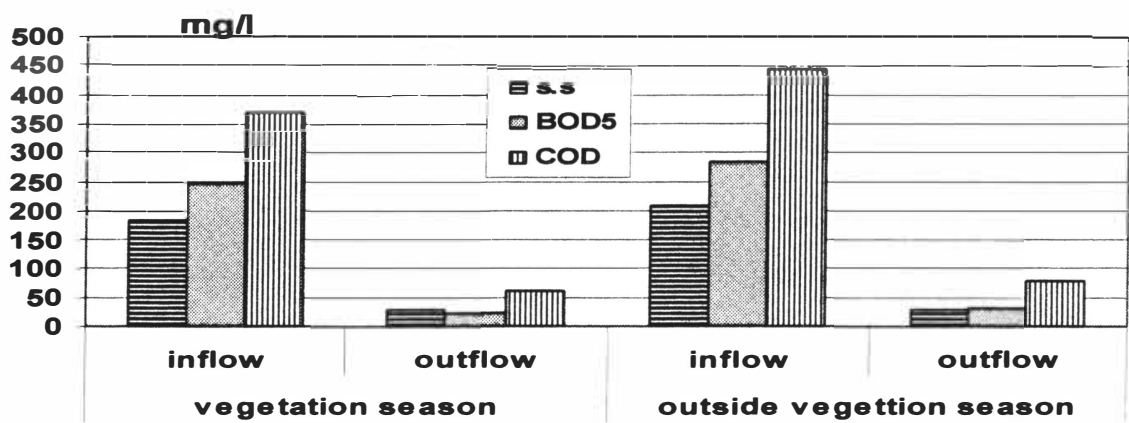


KALMAR ECO-TECH'03

Bioremediation and Leachate Treatment

KALMAR, SWEDEN, November 25-27, 2003

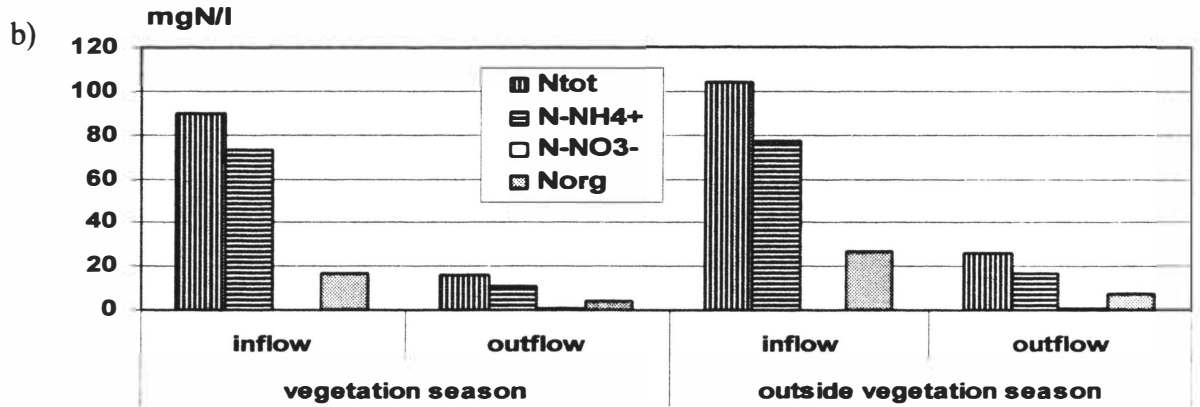

Fig. 3 The average concentration of organic matter (a) and nitrogen compounds (b) in sewage inflowing and outflowing from the facilities in Wiklino

Because of higher concentration of contamination and lower amount of sewage in outside vegetation season the load of contaminations discharged to the facilities in this season were higher than in adequate loads in vegetation one (Fig. 2).

The efficiency removal of different contamination did not varied very much in both seasons (Fig. 4). The biggest different were observed for nitrogen compounds removal. In the cease of ammonium nitrogen the efficiency in vegetation season was equal to $85.1 \%$ and in outside vegetation season decreased to $78.3 \%$ (Fig. 4).

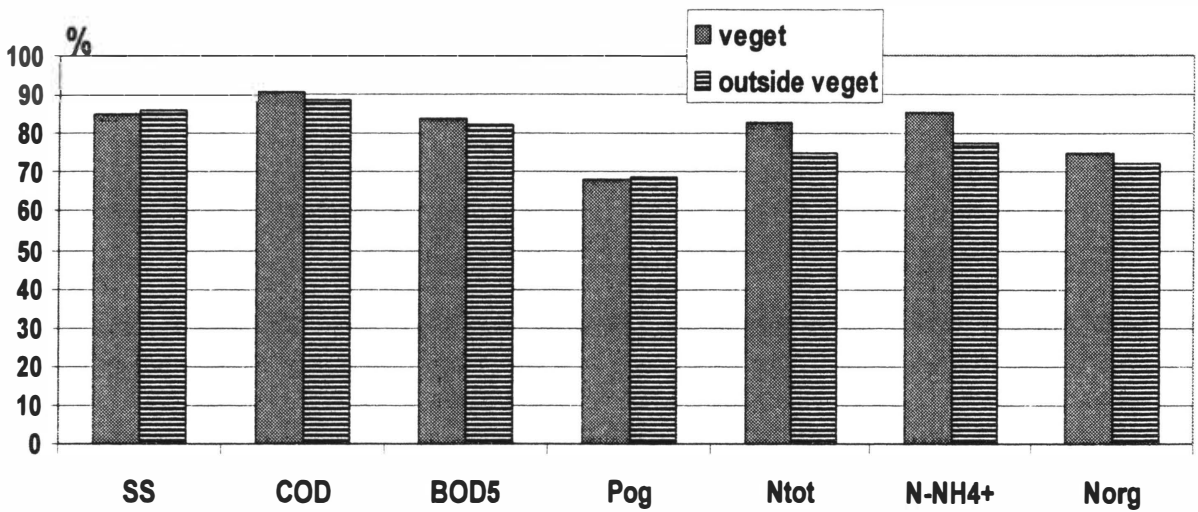


KALMAR ECO-TECH'03

Bioremediation and Leachate Treatment

KALMAR, SWEDEN, November 25-27, 2003

Fig. 4 Comparison of average efficiency removal of contaminations in vegetated and outside vegetation seasons in Wiklino facilities

The values of $k_{p(T)}$ for the temperature of $208 \mathrm{C}$, taking into account average monthly temperatures, were calculated using the relationship $\mathrm{k}_{\mathrm{p}(\mathrm{T})}=\mathrm{k}_{\mathrm{p}(20)}(1.1)^{\mathrm{T}-20}$. The obtained average values of reaction rate constant for the HF-CW I and HF-CW II beds and corresponding modified constant rates for VF-CW bed are given in Table 2 .

Table 2. The average values of analysed reaction rate constants in the temperature $20^{\circ} \mathrm{C}$, $d^{l}$ and $m d^{l}$

\begin{tabular}{l|c|c|c}
\multirow{2}{*}{$\begin{array}{c}\text { REACTION RATE } \\
\text { CONSTANTS }\end{array}$} & HF-CW I & HF-CW II & VF-CW \\
\cline { 2 - 4 } & \multicolumn{3}{|c}{ VEGETATION SEASON } \\
\hline $\mathrm{k}_{\mathrm{pBOD}(20)} / \mathrm{k}_{\mathrm{BOD}(20)}$ & 0.122 & 0.27 & 0.031 \\
\hline $\mathrm{k}_{\mathrm{pNtot(20}} / \mathrm{k}_{\text {Ntot(20) }}$ & 0.094 & 0.124 & 0.025 \\
\hline $\mathrm{k}_{\mathrm{pNorg}(20)} / \mathrm{k}_{\text {Norg(20) }}$ & 0.061 & 0.061 & 0.024 \\
\hline & \multicolumn{3}{|c|}{ OUTSIDE VEGETATION SEASON } \\
\hline $\mathrm{k}_{\mathrm{pBOD}(20)} / \mathrm{k}_{\mathrm{BOD}(20)}$ & 0.071 & 0.111 & 0.019 \\
\hline $\mathrm{k}_{\mathrm{pNtot}(20)} / \mathrm{k}_{\text {Ntot(20) }}$ & 0.045 & 0.062 & 0.019 \\
\hline $\mathrm{k}_{\mathrm{pNorg}(20)} / \mathrm{k}_{\text {Norg(20) }}$ & 0.048 & 0.052 & 0.018
\end{tabular}

The obtained values of reaction rate constant indicate that organic substances decomposition was the fastest process, while total nitrogen removal was slightly slower in both seasons. Mineralization of organic nitrogen was the slowest process, both during vegetation season and outside one. According to Obarska-Pempkowiak and Gajewska (2003) it was also proved that substantial part of organic nitrogen was amonificated in the septic tank. The temperature influence on the amonification process effectiveness was negligible. The average values of the constant rates $\mathrm{k}_{\mathrm{pBOD}}(20)$ and $\mathrm{k}_{\mathrm{pN} \text { tot(20) }}$ were by 42.0 and $52.0 \%$ higher in the vegetation season than outside it for the HF-CW I bed. For the $\mathrm{HF}-\mathrm{CW}$ II the average values of the constant rates were over $50 \%$ higher for the vegetation season than outside it.

The average values of modified constant $\mathrm{k}_{\mathrm{BOD}(20)}$ and $\mathrm{k}_{\mathrm{Ntot}(20)}$ in vegetation season were equal to 0.031 and $0.025 \mathrm{md}^{-1}$, respectively and were higher than in outside vegetation season. Similar results were obtained by Birkedal et al. (1993) for 37 VF-CW beds in Denmark. The average value of modified $k_{\mathrm{Ntot}(20)}$ constant rate was $0.0247 \mathrm{md}^{-1} \mathrm{e}$ (Birkedal et al., 1993). The values of $\mathrm{k}_{\mathrm{BOD}(20)}$ obtained during investigation carried out in Austria and Great Britain varied from 0.067 to $0.1 \mathrm{md}^{-1}$ and were higher than the values calculated for the VF-CW beds in Wiklino. This could result from higher average air temperature (Harbel et al., 1998, Cooper \& de Maeseneer, 1996) 


\subsection{DARŻLUBIE CONSTRUCTED WETLAND}

The seasonal changes of concentration of contaminations discharged to and from the Darżlubie facilities are presented on Fig. 5 The average concentration of contaminations discharged to the facilities in Darżlubie during outside vegetation season were lower than in vegetation season. The loads of contamination of inflowing sewage increased during the period of investigation. It was caused by pig manure begging discharged combine with domestic sewage from some farms. The agriculture production was more extensive during spring and summer and it caused higher concentration of contaminants during vegetation season. The biggest differences in discharged concentrations were observed for organic matter expressed by $\mathrm{BOD}_{5}$ and organic nitrogen. During the vegetation season the concentration of $\mathrm{BOD}_{5}$ and Norg were twice higher than in inflowing sewage than in outside vegetation season. The smallest differences in inflowing sewage were observed for total phosphorous: $8.5 \mathrm{mg} \mathrm{P} / 1$ in outside vegetation season and $9.9 \mathrm{mg} \mathrm{P} / 1$ in vegetation season.

The efficiency removal of chosen contaminations in vegetation season and in outside one is given in Fig. 6. During measurement period the efficiency removal of contamination was higher for outside vegetation period then in vegetation one. The biggest difference was observed for effectiveness of organic matter removal which was about $92.4 \%$ for outside vegetation season and only $75.2 \%$ for vegetation season. In case of ammonium nitrogen and total phosphorus the difference did not exceed $5 \%$. It was probably caused by too high concentration of pollutants discharged during the period. High load of organic matter in colloidal form caused clogging of the HF-CW I filter and resulted in decrees of efficiency removal of all facility (Obarska-Pempkowiak and Ozimek 2000).

Only organic nitrogen was more effective removed during vegetation season ( $86.4 \%)$ than during outside vegetation one $(78.5 \%)$.

a)

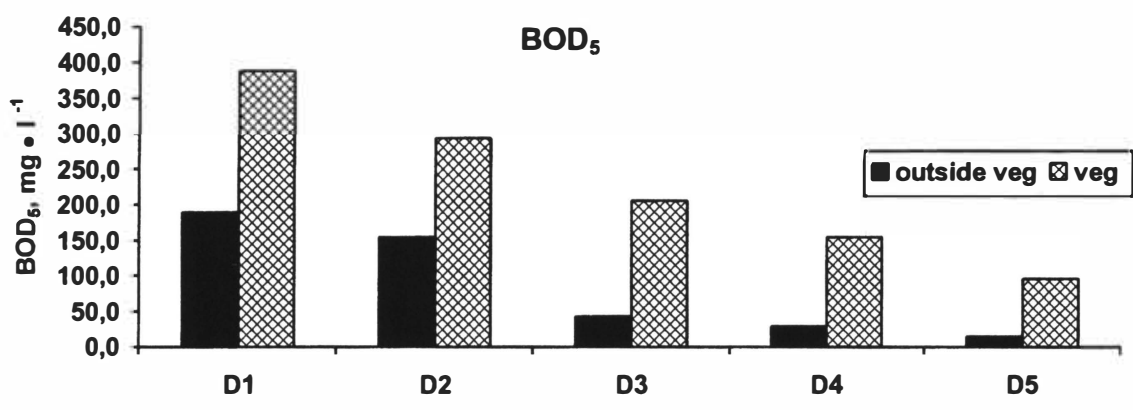


KALMAR ECO-TECH'03

Bioremediation and Leachate Treatment

KALMAR, SWEDEN, November 25-27, 2003

b)

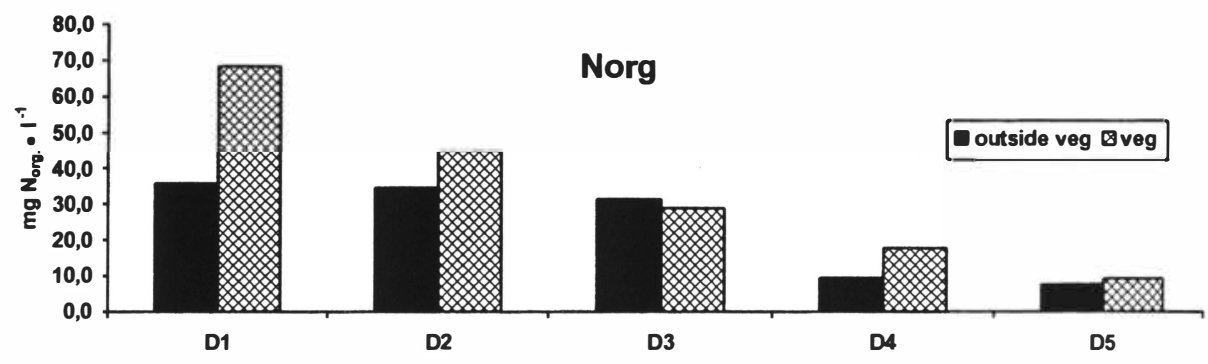

c)

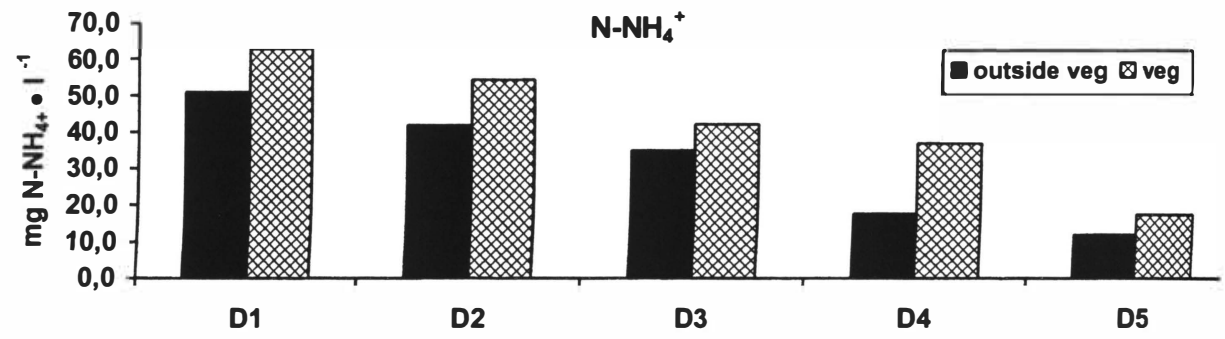

d)

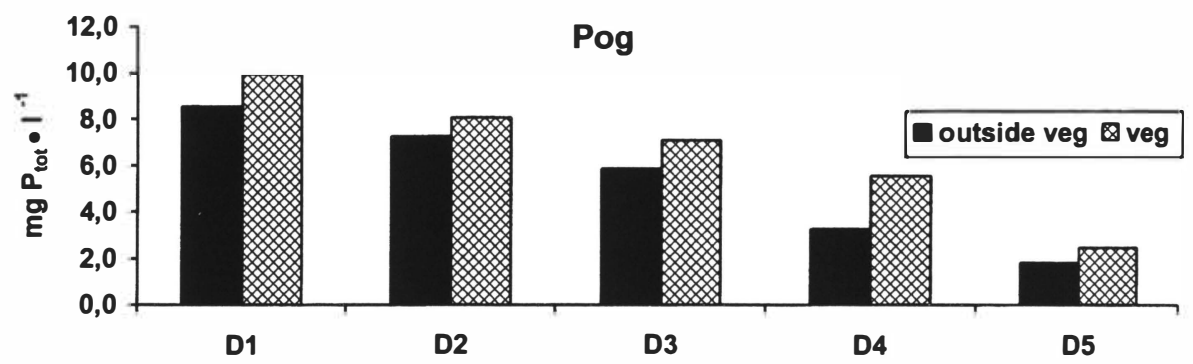

Fig. 5 The average concentration of organic matter (a), organic nitrogen (b), ammonium nitrogen (c) and total phosphorus (d) in sewage in Darżlubie in vegetation and outside vegetation season after subsequent stage of treatment (D1-D5) 


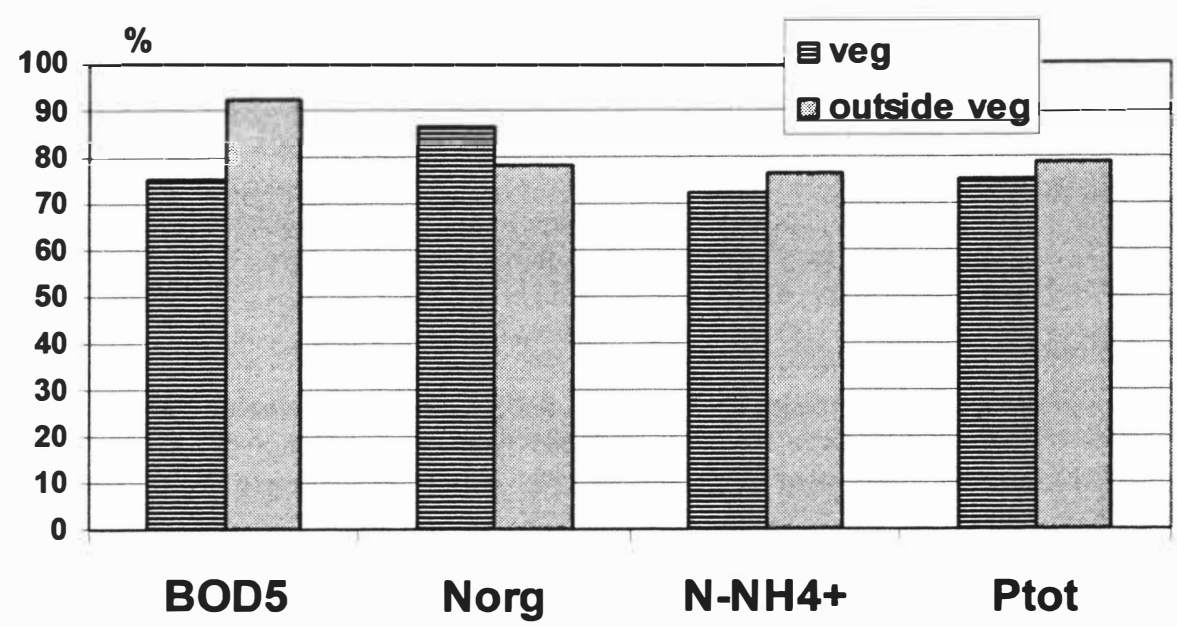

Fige 6 Comparison of average efficiency removal of contaminations in vegetated and outside vegetation seasons in Darżlubie facilities

\section{CONCLUSIONS}

1. Temperature of air and sewage did not substantially affect nitrogen removal. The average effectiveness of ammonia nitrogen removal in vegetation were about $85 \%$ for Wiklino facility and $72.2 \%$ for Darżlubie, while in outside vegetation were respectively $78.0 \%$ and $76.4 \%$

2. The decrease of effectiveness of nitrogen transformation process in outside vegetation season is confirmed by the values of reaction constant rates which in case of Wiklino facility were equal to $60 \%$ of the values reached in vegetation season.

3. In case of Darżlubie improper maintenance of the system caused clogging of same filters and resulted in decrees of efficiency removal of the whole facilities.

4. The outflow from Wiklino in both seasons did not exceed new polish standards while in Darżlubie concentration of organic matter $\left(\mathrm{BOD}_{5}\right)$ in vegetation season exceeded permissible value because of too concentration of pig manure in inflowing sewage.

\section{ACKNOWLEDGEMENTS}

The authors wish to thank the State Committee for Scientific Research for financing of the investigation included in the research project 4 T $09 \mathrm{C} 04222$ 


\section{REFERENCES}

[1] Birkedal K., Brix H., Johansen N.H., 1993 Wastewater treatment in constructed wetlands. Designers manual. Danish-Polish Post-Graduate Course on "Low technology wastewater treatment" Technical University of Gdańsk, Poland

[2] Cooper P., de Maeseneer J., 1996, Hybrid systems -what is the best way to arrange the vertical and horizontal-flow stage? IAWQ Specialist Group on Use of Macrophytes in Water Pollution Control, December 1996,: 8-13

[3] Haberl R., Perfler R., Laber J., Grabher D., 1998 Austria. Vymazal J., Brix H., Cooper P.F., Green M.B., \& Haberl R., (Ed.) In: Constructed wetlands for wastewater treatment in Europe. Backhuys Publishers, Leiden , :67-76

[4] Obarska-Pempkowiak H., Ozimek T., 2000 Efficiency of wastewater treatment in an improved constructed wetland, Polish Arch. Hydrobiology 47,247-256

[5] Obarska-Pempkowiak H., Gajewska M., 2003, Fluctuations in the organic matter decomposition rate and nitrogen speciation in vegetation and outside vegetation seasons in a hybrid wetland system, (Eds.) Ulo Mander, Christina Vohla and Age Poom In: Conference proceedings, EU $5^{\text {th }}$ FP RTD PRIMROSE "Process Based Integrated Management of Constructed and Riverine Wetlands for Optimal Control of Wastewater at Catchment Scale" 